\title{
Condiciones de control, fuentes de contaminación y agentes desinfectantes empleados en una sala blanca
}

\author{
Control conditions, contamination sources and disinfectant agent utilized in a clean white room
}

\author{
Erick Vargas Valverde ${ }^{1}$ \\ Recibido: 21/11/2016 / Aprobado: 23/5/2017
}

\begin{abstract}
Resumen
Una sala blanca o limpia es un área científicamente construida para trabajar en condiciones de asepsia; es así como las instalaciones nucleares, microelectrónicas, alimentarías, cosméticas, de bioseguridad, farmacias de formulación magistral, de terapia celular, las instalaciones de metrología, laboratorios de investigación tecnológica y las industrias farmacéuticas las utilizan. Específicamente en la industria farmacéutica, para garantizar las condiciones en los laboratorio donde se realizan las pruebas de esterilidad, se deben conocer los principales factores para el control, operación y desinfección de las salas blancas, los cuales mantienen la concentración de partículas en niveles aceptables de contaminación. Factores como la presión y la recirculación interna del aire en la sala, sumados con la regulación de la temperatura, humedad y el control de la vestimenta del personal de trabajo son idispensables para una adecuada operación. Por su parte, desinfectantes a base de alcohol, fenol, cloro, amonio cuaternario, formaldehido, glutaraldehído, peróxido de hidrógeno y perácidos son comúnmente utilizados para la desinfección de paredes, pisos y mesas de trabajo. Este trabajo contempla los principales factores de control, operación y desinfección de una sala blanca aplicados en un laboratorio de pruebas de esterilidad en la industria farmacéutica.
\end{abstract}

Palabras clave: sala blanca, industria farmacéutica, condiciones de asepsia, bioseguridad

\section{Abstract}

A white room or a clean one is a scientific space built to work in aseptic conditions, that is how nuclear facilities, microelectronics, food, cosmetic, biosafety, master-formulating pharmacies, cell therapy, metrology facilities, technological research laboratories and pharmaceutical industries used them. In the pharmaceutical industry specifically, in order to guarantee conditions in laboratories where sterility tests are carried out, people must know the control, operation and disinfection of the white rooms which keep the concentration of particles in acceptable levels of contamination.Besides, factors such as pressure and internal recirculation of the air in the room, plus the regulation of temperature, humidity and the control of staff clothing are a priority for a proper operation. Meanwhile disinfectants based on alcohol, phenol, chlorine, quaternary ammonium, formaldehyde, glutaraldehyde, hydrogen peroxide and peracids are commonly used to disinfect walls, floors and working tables. This study considers the main factors of control, operation and disinfection of a white room apply in a laboratory of sterility tests in the pharmaceutical industry.

Key Words: Clean room, pharmaceutical industry,asepsis conditions, biosecurity

\footnotetext{
${ }^{1}$ Bachiller en Laboratorista Químico. Estudiante de Licenciatura en Laboratorista Químico, Sede de Occidente, Universidad de Costa Rica. Caja Costarricense de Seguro Social, Laboratorio de Normas y Calidad de Medicamentos. San José, Costa Rica. Correo electrónico: erick-var@hotmail.com
} 


\section{Introducción}

Una sala blanca, sala limpia, sala estéril o "cleanroom" como se conoce en inglés, es un área científicamente construida para trabajar en condiciones de asepsia. Son utilizadas por las industrias farmacéuticas, nucleares, microelectrónicas, alimentarias, cosméticas, de bioseguridad, farmacias de formulación magistral, de terapia celular, las instalaciones de metrología, laboratorios de investigación tecnológica, quirófanos de hospitales y están diseñadas para garantizar la exclusión microbiana y prevenir la contaminación de materiales estériles, componentes y superficies en operaciones asépticas y conjuntamente con la exclusión debe conseguir una limitación microbiana en las zonas ocupadas próximas a operaciones asépticas (Comas, 2012).

En la sala blanca se controla la concentración de partículas contenidas en el aire, además su construcción y utilización se realiza de forma tal que el número de partículas introducidas o generadas y existentes en el interior del local sean lo menor posible. Además, se puedan controlar otros parámetros importantes como temperatura, humedad y presión ( $\mathrm{Pi}, 2006)$.

Existen normativas que clasifican las salas blancas, a saber; la ISO 14644 o la que realiza la "Guía de Normas de Correcta Fabricación aplicables a industrias farmacéuticas" (GMP, Good Manufacturing Practice, por sus siglas en inglés). Estas normativas definen una cantidad de partículas para un área; así por ejemplo, una sala con una concentración de 352000 partículas $/ \mathrm{m}^{3} \mathrm{y}$ con un tamaño mayor o igual a 0,5 micrómetros definida como una clase ISO 7, tiene su equivalencia en la GMP a una clase Grado C, o una clase ISO 8 que tiene una concentración de 3520000 partículas/ m3 será una clase Grado D en la GMP (Agencia Española de Medicamentos y Productos Sanitarios, 2009). En Costa Rica, el ente encargado de regular las áreas limpias es el Ministerio de Salud y ha emitido un documento de buenas prácticas de manufactura para la industria farmacéutica, para lo cual sigue las recomendaciones de la Organización Mundial de la Salud, número 32, que recomienda utilizar la clasificación de áreas limpias propuesto por GMP (Reglamento Técnico Centroamericano, 2007).

La clasificación empleada por las normativas para las salas limpias toma como base, la cantidad y el tamaño de las partículas presentes en el ambiente, tanto en estado de reposo como en operación (Kochevar, 2006.) La importancia que adquiere esta variable obedece a que las partículas se pueden acumular sobre superficies producto de la gravedad y por la adherencia electroestática. En los líquidos se adhieren a las burbujas de aire; también pueden pegarse a las paredes de un conducto o recipiente $\mathrm{o}$ aglutinarse en una masa más grande (Kochevar, 2006).

En este sentido el límite de clasificación considerada por la GMP de 0,5 micras y 5 micras reside en el hecho de que es conocido que partículas $\geq$ $0,5 \mu \mathrm{m}$ son capaces de transportar microorganismos que en general miden 0,3 $\mu \mathrm{m}$ (Colomé, 2005). Las partículas que son aerotransportadas poseen formas variables y están compuestas de todo tipo de materiales $(\mathrm{Pi}, 2006)$. Además pueden actuar como "transportadores" de bacterias, De ahí que se distinga entre partículas viables y partículas no viables o inertes. (Pi, 2006) Como ejemplos de partículas viables están: bacterias, mohos, hongos y esporas. Las partículas no viables incluyen sustancias tales como compuestos orgánicos, metales, compuestos inorgánicos y sal marina. (Echeverri y Maya, 2008).

Un aspecto importante que se denota en la guía de Normas de Control de Fabricación de Medicamentos Microbiológicos, publicado por la Agencia Española de Medicamentos y Productos Sanitarios en el 2009 y que es extendido a todo tipo de salas blancas, es el control microbiológico ambiental; por ello se recomienda la utilización de filtros HEPA (High Efficiency Particle Arrestance, por sus siglas en ingles), los cuales realizan la función de purificación del aire al retener las partículas. 
Por otra parte, se recomienda la utilización de desinfectantes variados en paredes, pisos y mesas de trabajo los cuales garantizan el control microbiológico en la sala blanca y se mantenga en los parámetros establecidos para la clasificación asignada. Entre los desinfectantes se citan: los fabricados a base de fenol, alcohol, formaldehído, glutaraldehído, cloro, amonio cuaternario, peróxido de hidrogeno y perácidos.

El objetivo de este trabajo es indagar sobre las principales fuentes de contaminación en una sala blanca diseñada para ejecutar las pruebas de esterilidad en medicamentos, los diferentes tipos de desinfectantes que se utilizan para desinfectar paredes, pisos y mesas de trabajo así como los elementos esenciales de control de operación que hacen que funcione correctamente.

\section{Salas blancas}

Las salas blancas fueron utilizadas inicialmente para el procesado de productos farmacéuticos, nucleares y miroelectrónicas. Sin embargo, dada la globalización de productos industriales como las alimentarias, las cosméticas, las de bioseguridad, las de formulaciones magistrales de las farmacias, las de terapia celular, las instalaciones de metrología, los laboratorios de investigación tecnológica entre otras, hace que se necesiten salas limpias para la realización del proceso, minimizando los rechazos debidos a contaminación, y maximizando las cualidades de los productos o investigaciones (Fernández, 2011)

La clasificación de las salas blancas se realiza con base a la cantidad de partículas que se encuentran en el aire, así para un laboratorio clase ISO 5 la cantidad máxima de partículas por metro cúbico para tamaños mayores o iguales a $0,5 \mu \mathrm{m}$ es de 3 520. (Corral, 2013) En el cuadro 1 se muestra la clasificación de la ISO 14644-1 para las salas blancas.
Para el sector farmacéutico es más habitual clasificar las salas blancas en grados (Fuentes, 2013):

A (Zona donde se realizan operaciones con alto riesgo de contaminación microbiológica) B Eentorno para la zona de grado A en el caso de preparación y llenado asépticos),

C y D (zonas limpias para realizar fases menos críticas en la fabricación de productos estériles).

Es de suma importancia velar porque la sala blanca permanezca dentro de los parámetros de clase o clasificación para la cual fue diseñada. Así para una sala blanca farmacéutica, donde se realiza el ensayo de esterilidad en producto terminado, la clasificación corresponde a la normativa ISO 5 para un flujo de aire unidireccional, en el cual, la cantidad de unidades formadoras de colonias (ufc) no debe ser mayor a $1 \mathrm{ufc} / \mathrm{m}^{3}$. (Red Panamericana de Armonización de la Reglamentación Farmacéutica, 2013).

\section{Fuentes de contaminación}

Las fuentes de contaminación más comunes en las salas blancas dependen de la procedencia y la importancia de conocer el origen de la contaminación es precisamente el hecho de controlar el ingreso de contaminantes y garantizar la asepsia del lugar. Los orígenes más comunes son los siguientes (Pedroza, 2012):

-La atmosfera, es fuente de contaminantes como: partículas, gases, humedad y calor. -El agua, contiene los metales pesados, las bacterias, electrolitos.

-Las personas, compuesta por el personal que labora en la sala y que son portadores de contaminantes como: partículas (caspa pelusa), maquillaje, fijador para el cabello y algunos químicos provenientes del sudor. -Otros de tipo particular como químicos, gases y el área de trabajo en sí. 
Las partículas suspendidas en el aire son la principal fuente de contaminación, el determinar su procedencia facilita el proceso de control microbiológico y asegura una mayor confiabilidad en los ensayos de esterilidad de medicamentos. En el cuadro 2 se resume los tres tipos de partículas que por su naturaleza están presentes en una sala blanca (Kochevar, 2016)

\section{Desinfección de Salas Blancas}

A pesar de las medidas de seguridad para el personal y el área de la sala limpia, resulta de suma importancia mantener protocolos de limpieza para evitar así la acumulación de polvo, suciedad, y minimizar la contaminación secundaria. Los protocolos de limpieza contemplan el uso de desinfectantes, de manera que para ser considerado como tal, el agente usado en el proceso de desinfección debe reducir la contaminación microbiana inicial de 3 a 5 logaritmos. Además debe promover la destrucción de causantes infecciosos o contaminantes, tanto en objetos como en ambientes y garantizar la eliminación de formas vegetativas sin incluir esporas bacterianas (Casanova, 2013). Los desinfectantes actúan de diferentes formas, unos lo hacen sobre la pared y membrana celular (interna o externa), otros sobre el núcleo y otros lo hacen sobre las enzimas o proteínas (Cabrera, Gómez y Zúñiga, 2007). En el cuadro 3 se presenta un resumen de sitio de acción, según diferentes desinfectantes empleados:

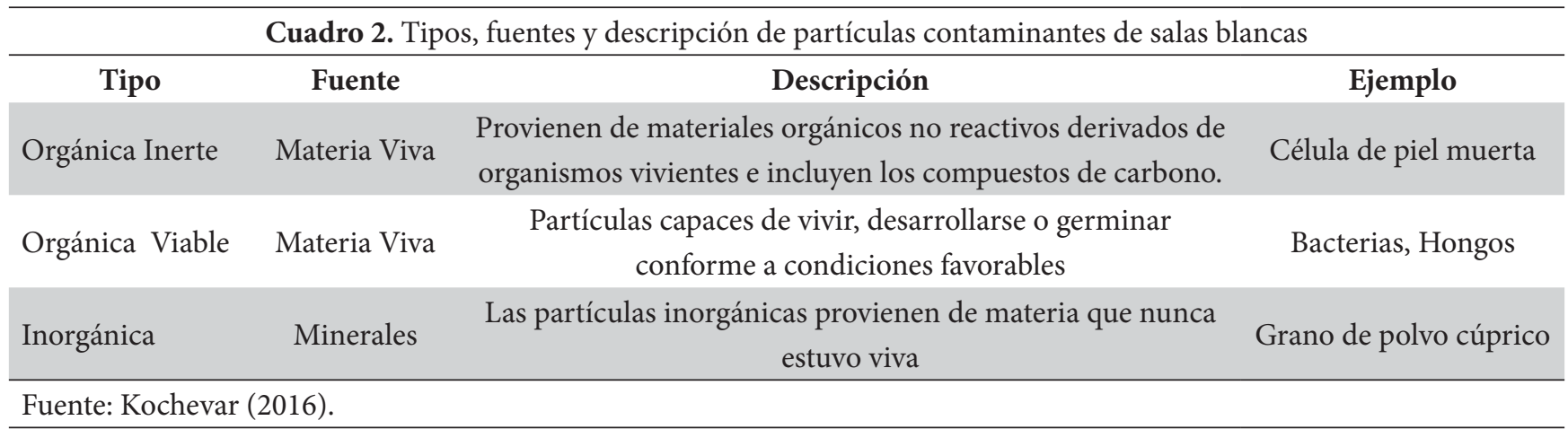

Cuadro 3. Sitio de acción del desinfectantes en los microorganismos

Sitio banco

Envoltura celular (pared celular, membrana externa)

Membrana interna citoplasmática

\begin{tabular}{l} 
Unión cruzada a macromoléculas \\
\hline Intercalación con el ADN \\
\hline Intercalación con grupos tiol \\
\hline
\end{tabular}

Efectos en el ADN

Agentes oxidantes

Fuente: (Cabrera, Gómez y Zúñiga, 2007).

\section{Antisépticos o desinfectantes}

Glutaraldehído

EDTA, otros permeabilizantes

Compuesto de Amonio Cuaternario (CAC)

Clorhexidina

Diaminas

Mezcla heterodispersa de bioguanidas de polihexametileno, alexidina

Fenoles

Formaldehído

Glutaraldehído

Acridinas

Compuestos con plata

Halógenos

Peróxido de hidrogeno, iones de plata

Halógenos

Peroxígenos 
Para maximizar el uso del desinfectante, es importante considerar su eficacia y esta depende de la cinética de destrucción, en la que se destacan los siguientes aspectos: la concentración del desinfectante, el tiempo de exposición, el pH del medio, la temperatura, la presencia de materiales extraños, la resistencia propia de los microorganismos y el número inicial de la población (Vignoli, 2006). Por otra parte, en la Secretaria General de Salud de Bogotá se recomienda considerar varios aspectos para la selección del desinfectante, entre los que se destacan, el ingrediente activo-concentración, la actividad microbiana, la descripción del producto, la biodegradabilidad, la compatibilidad con las superficies, el tiempo de acción, la forma y el campo de aplicación, el valor agregado y el aspecto económico (Secretaría general de salud de Bogotá, 2004).

Los desinfectantes cumplen una tarea muy importante dentro del marco operativo de una sala blanca, cuando garantizan la sanidad de las áreas de trabajo. Algunos productos utilizados como desinfectantes cuyas características, ventajas, desventajas y concentraciones recomendadas son expuestas en el cuadro 5 (Martí, Alonso y Constans, 1994; Rueda, Amigot y Ducha, 2003; OMS, 2005 y Agencia Nacional de Vigilancia Sanitaria, 2010).

\begin{tabular}{|c|c|c|c|}
\hline \multicolumn{4}{|c|}{ Cuadro 2. Tipos, fuentes y descripción de partículas contaminantes de salas blancas } \\
\hline Desinfectante & Características & Desventaja & Concentración \\
\hline $\begin{array}{l}\text { Alcohol (Etílico, } \\
\text { Isopropílico) }\end{array}$ & $\begin{array}{l}\text { Bactericida, virucida, fungicida y } \\
\text { tuberculicida. } \\
\text { No actúa sobre las esporas. } \\
\text { Funciona de manera inmediata y es de } \\
\text { fácil aplicación. } \\
\text { Actúa por desnaturalización de la } \\
\text { proteína de la pared celular. }\end{array}$ & $\begin{array}{l}\text { Es inflamable. } \\
\text { Opaca el acrílico. } \\
\text { Reseca los plásticos y gomas. } \\
\text { Reseca la piel }\end{array}$ & Entre $60 \%$ y $90 \%$ \\
\hline $\begin{array}{l}\text { Compuestos } \\
\text { fenólicos }\end{array}$ & $\begin{array}{l}\text { Es un bactericida, virucida, } \\
\text { micobactericida y fungicida. } \\
\text { No es esporicida. } \\
\text { Presenta acción residual (que perdura } \\
\text { por un período luego de su aplicación) } \\
\text { Actúa rompiendo la pared de las células } \\
\text { precipitando las proteínas celulares. } \\
\text { En bajas concentraciones inactiva } \\
\text { las enzimas, interfiriendo con el } \\
\text { metabolismo de la pared celular }\end{array}$ & $\begin{array}{l}\text { Está prohibida su utilización en áreas } \\
\text { de contacto con alimentos debido a la } \\
\text { toxicidad oral. } \\
\text { Es irritante de piel y mucosas } \\
\text { respiratorias y oculares. } \\
\text { Tienen efecto alergénico y } \\
\text { fotosensibilizante. }\end{array}$ & $\begin{array}{l}\text { Soluciones de } \\
5 \mathrm{mg} / 1\end{array}$ \\
\hline $\begin{array}{l}\text { Compuestos } \\
\text { liberadores de } \\
\text { cloro activo }\end{array}$ & $\begin{array}{l}\text { Es un bactericida, virucida, fungicida, } \\
\text { tuberculicida y esporicida dependiendo } \\
\text { de la concentración que se utilice. } \\
\text { Tiene un amplio espectro y es de rápida } \\
\text { acción } \\
\text { Se clasifican en orgánico e inorgánico } \\
\text { según su origen }\end{array}$ & $\begin{array}{l}\text { Es corrosivo a metales en altas } \\
\text { concentraciones }\end{array}$ & $\begin{array}{l}\text { Inorgánico: } 0.02 \% \\
\text { y } 1.0 \% \\
\text { Orgánico: } 1.9 \% \text { y } \\
6.0 \%\end{array}$ \\
\hline
\end{tabular}




\begin{tabular}{|c|c|c|c|}
\hline Desinfectante & Características & Desventaja & Concentración \\
\hline $\begin{array}{l}\text { Compuestos } \\
\text { de amonio } \\
\text { cuaternario }\end{array}$ & $\begin{array}{l}\text { Es un bactericida, fungicida y virucida } \\
\text { (del tipo lipofílico). } \\
\text { Poseen su mecanismo de acción } \\
\text { mediante la inactivación de } \\
\text { enzimas productoras de energía, La } \\
\text { desnaturalización de las proteínas y la } \\
\text { ruptura de la membrana celular }\end{array}$ & $\begin{array}{l}\text { Se puede inactivar en presencia de } \\
\text { materia orgánica. }\end{array}$ & $\begin{array}{l}\text { Soluciones de } 1 \\
\mathrm{mg} / \mathrm{l}\end{array}$ \\
\hline Formaldehido & $\begin{array}{l}\text { Es un gas que mata todos los } \\
\text { microorganismos y esporas a } \\
\text { temperaturas superiores a los } 20^{\circ} \mathrm{Cy} \\
\text { humedades relativas superiores al } 70 \% \text {. }\end{array}$ & Irrita ojos y las mucosas & $\begin{array}{l}\text { Forma solida } \\
\text { (paraformaldehído) } \\
\text { y en solución al } \\
37 \%\end{array}$ \\
\hline Glutaraldehído & $\begin{array}{l}\text { Actividad en contra de formas } \\
\text { vegetativas de bacterias, esporas, hongos } \\
\text { y virus con y sin envoltura lipídica. } \\
\text { Trabaja más rápido que el formaldehido } \\
\text { sin embargo tarda más en matar las } \\
\text { esporas bacterianas. }\end{array}$ & $\begin{array}{l}\text { Requiere ser activado con compuestos } \\
\text { de bicarbonato y se logra una } \\
\text { estabilidad de } 4 \text { semanas. } \\
\text { Es toxico e irritante de la piel y } \\
\text { mucosas }\end{array}$ & Soluciones al 2\% \\
\hline $\begin{array}{l}\text { Peróxido de } \\
\text { hidrógeno y } \\
\text { perácidos }\end{array}$ & $\begin{array}{l}\text { Son oxidantes energéticos y potentes } \\
\text { germicidas de amplio espectro. } \\
\text { Son inocuos para el hombre y el medio } \\
\text { ambiente. } \\
\text { Es un desinfectante lento. } \\
\text { El peróxido de hidrógeno se puede } \\
\text { utilizar para desinfectar superficies de } \\
\text { trabajo de laboratorio. }\end{array}$ & $\begin{array}{l}\text { Se descompone muy fácilmente } \\
\text { y deben ser protegidos de la luz y } \\
\text { almacenados en lugares frescos }\end{array}$ & $\begin{array}{l}\text { Soluciones } \\
\text { preparadas diluidas } \\
\text { al } 3 \% \text { lista para } \\
\text { usarse } \\
\text { Concentraciones } \\
\text { del } 30 \% \text { la cual } \\
\text { se diluye en agua } \\
\text { estéril hasta lograr } \\
\text { concentraciones } \\
\text { entre el } 3 \text { y } 6 \% \text {, }\end{array}$ \\
\hline
\end{tabular}

Fuente: (Martí, Alonso y Constans, 1994; Rueda, Amigot y Ducha, 2003; OMS, 2005 y Agencia Nacional de Vigilancia Sanitaria, 2010).

\section{Condiciones de operación de las salas blancas}

Anteriormente, se indicó que las partículas del aire son la principal causa de contaminación en salas blancas. En un ambiente promedio aplicado a una ciudad media, el aire posee entre doscientas mil y diez millones de partículas micrónicas en suspensión por cada pie cubico (Melo, 2009). Para garantizar un buen desempeño en las salas limpias, Fuentes (2013) indica que es necesario tomar medidas de seguridad, ya que la naturaleza contaminante de las partículas puede provocar que la contaminación se presente rápidamente en toda la sala blanca. Según Fuentes (2013), dentro de las medidas de seguridad se citan:

- Utilizar filtros HEPA o ULPA para retener partículas, filtros de alta eficiencia en la retención de partículas.

- Ingresar aire estéril a la sala limpia, esto se logra filtrando las partículas suspendidas del aire; este proceso se debe repetir varias 
veces por hora para evitar la acumulación de partículas. En este sentido Garcia-Therán (2014), indica que la tasa de renovación de aire varía desde 30 por hora en locales de clase 100.000 (ISO 8) hasta 600 a 720 por hora en locales de clase 100 (ISO 5). (García-Therán, 2014)

- Los rincones son redondeados y las paredes están recubiertas de vinilo y para evitar acumulaciones de suciedad.

- Los trabajadores deben vestirse con trajes especiales para no llevar contaminantes ni generar partículas de polvo.

- Debe existir esclusas que separen las salas limpias y el exterior.

- La presión atmosférica interna de las salas se mantiene ligeramente superior a la del exterior.

Según se indicó, uno de los puntos importantes de control en la sala blanca es la presión del área, debido a la necesidad de evitar el ingreso de partículas contaminantes provenientes del exterior. Al mantener una presión de la sala mayor que la de sus alrededores, cuando se abre una puerta o ventana, el aire fluirá de adentro de la sala hacia afuera y no habrá migración de partículas hacia el interior (Moia \& Wheeler, 2000).

En términos generales, una diferencia de presión entre una sala limpia y el aire ambiente de $15 \mathrm{~Pa}$ es suficiente para eliminar la migración de partículas y puede llegar hasta un máximo de 45 $\mathrm{Pa}$. A mayores presiones la sala sufre por problemas mecánicos y por ruido cuando se producen fugas. (Moia \& Wheeler, 2000)

Otro factor que se debe contemplar en una sala limpia es controlar las condiciones del ambiente, la temperatura y la humedad. Los ambientes secos favorecen la permanencia de bacterias cocos gram positivos, mientras que la humedad fomenta el crecimiento de bacilos gram negativos y los hongos presentes en el polvo. (Lama, 2012).
El control que se ejerza sobre la vestimenta del personal que trabaja en la sala blanca es importante. Este factor constituye una fuente de contaminación importante, se requiere de equipo especializado. Según las buenas prácticas de manufactura establecidas por las OMS, la vestimenta a utilizar en una sala blanca de clase A y B (sala de alta bioseguridad) emplea una cofia que cubra completamente el cabello y, se debe cubrir la barba y el bigote. Además es necesario considerar los siguientes aspectos (OMS, 2001):

1. Se debe usar un traje de una sola pieza, cerrado en las muñecas y con un cuello alto.

2. La parte inferior de la cofia se debe meter en el cuello del traje.

3. Se debe utilizar una mascarilla para evitar el derramamiento de gotitas.

4. Se deben portar guantes del material apropiado, esterilizados, sin talco, y calzado esterilizado o desinfectado.

5. Las terminaciones del pantalón se deben de meter dentro del calzado y las bocamangas del traje se deben meter dentro de los guantes.

6. La ropa de protección no debe desprender prácticamente fibra o particular alguna y debe retener las partículas eliminadas por el cuerpo.

Por otra parte, Fuentes (2013) señala que los operarios deben vestirse con trajes especiales para no llevar contaminantes ni generar partículas de polvo. Los trajes especiales comprenden: gorro, mascarilla, ropa de quirófano, guantes de látex y calzas de plástico. Según lo indicado por la Agencia Española de Medicamentos y Prodcutos Sanitarios (2009) las condiciones para el personal que labora en salas limpias de clasificación A y B son las siguientes:

1. Cubrir totalmente con un tocado el cabello (barba y bigote) y este introducirse dentro del traje.

2. Debe utilizarse una máscara para evitar la emisión de gotitas. 
3. Se utilizarán guantes apropiados esterilizados de goma o plástico, sin polvos de talco.

4. Se debe llevar calzado esterilizado o desinfectado.

5. Las partes inferiores de los pantalones se introducirán en el calzado y las mangas en los guantes.

6. La vestimenta protectora no debe liberar prácticamente ninguna fibra ni partícula y debe retener las partículas desprendidas por el cuerpo.

\section{Conclusiones}

Las salas blancas son áreas diseñadas y construidas científicamente para ser utilizadas por los sistemas modernos de producción para garantizar productos más limpios, libres de bacterias, hongos, esporas y otros. Es necesario controlar la presión en estos sitios, una presión mayor a la parte externa, evitará que ingresen contaminantes a la sala al abrir las puertas y ventanas.

El control ambiental de temperatura y humedad es crítico debido a que las bacterias y hongos que puedan estar presentes en las mesas, paredes, pisos, ventanas, puertas, requieren de estas condiciones para su reproducción y proliferación. De esta manera pueden llegar a las manos del personal y afectar la prueba de esterilidad.

Las partículas presentes en una sala blanca provienen de fuentes orgánicas e inorgánicas; son viables si transportan microorganismos y promueven la proliferación de microorganismo o no viables si es contrario.

El personal que se moviliza dentro o trabaja en una sala blanca, debe protegerse con una vestimenta especialmente diseñada, que cubra la cabeza, la cara, las manos, el cuerpo, los zapatos, no debe quedar ninguna parte del cuerpo expuesta debido a que el cuerpo libera partículas las cuales pueden contaminar la sala.
A pesar de los controles presentes en la sala blanca, el ingreso de partículas aéreas es inevitable, y su acumulación promoverá la multiplicación de microorganismos, por lo tanto, se hace obligatorio utilizar agentes químicos de desinfección para garantizar que las bacterias, hongos, esporas y virus, se eliminen para la operación de la sala blanca.

Los productos más comúnmente utilizados como desinfectantes de paredes, pisos y mesas de trabajo, son aquellos en el cual el principio activo es el alcohol, el fenol, el cloro, el amonio cuaternario, el formaldehido, el glutaraldehído y el peróxido de hidrógeno y perácidos. El uso de uno u otro dependerá del tipo de microorganismo presente y la resistencia de estos hacia los desinfectantes utilizados.

\section{Referencias bibliográficas}

Agencia Española de Medicamentos y Productos Sanitarios. (2009). Anexo 1 Fabricación de medicamentos estériles. En Guía de Normas de Correcta Fabricación de Medicamentos de uso Humano y Veterinario. Madrid

Agencia Nacional de Vigilancia Sanitaria. (2010). Segurança do paciente em serviços de saúde: limpeza e desinfecção de superficies. Brasilia

Cabrera, C., Gómez, F. y Zúñiga, A. (2007). “La resistencia de bacterias a antibióticos, antisépticos y desinfectantes una manifestación de los mecanismos de supervivencia y adaptación”. Colombia Médica, 38 (2) 149-158.

Casanova, V. (2013). Métodos de limpieza, desinfección y esterilización Su utilización en la práctica profesional del Técnico para Bioterio. Recuperado de http://www.bioterios. com/2013/post.php?s=2013-07-01-mtodosde-limpieza-desinfeccin-y-esterilizacin 
Colomé, E. (2005). Sales blanques a la indústia de l'alimentació. I Congrés EBA 2005, Enginyeria I Biologia dels Aliments: Processos I Conservació. Barcelona.

Comas, V. (2012). Las salas blancas en la industria farmacéutica. Recuperado de http://www. interempresas.net/Farmacia/Articulos/99312Las-salas-blancas-en-la-industriafarmaceutica.html.

Corral, J. (2013). Guía para la formulación magistral de medicamentos estériles en la oficina de farmacia. Revisión y actualización del estado de la técnica en preparados oftálmicos.

Echeverri, C. y Maya, G. (2008). “Relación entre las partículas finas (PM 2.5) y respirables (PM 10) en la ciudad de Medellín”. Revista Ingenierías Universidad de Medellín, 7(12), 23-42.

Fernández-Virgel, B. (2011). "Las Salas Blancas ¿Quién? ¿Por qué? ¿Para quién?”. Farmespaña Industrial, marzo/abril 11: 44-46.

Fuentes, M. (2013). Limpieza de salas blancas. Empresa y Limpieza. Recuperado de http:// empresaylimpieza.com/not/771/limpieza-desalas-blancas/

García-Therán, J. A. (2014). Diseño de un sistema de acondicionamiento de aire para la preparación de medicamentos especiales para una empresa farmacéutica. (Trabajo de grado). Universidad Autónoma del Caribe, Barranquilla, Colombia.

Kochevar, S. (Enero de 2006). Guía básica a la tecnología de partículas. Recuperado de https://www.academia.edu/20071578/ Gu\%C3\%ADa_b\%C3\%A1sica_a_la_tecnolog \%C3\%ADa_de_part\%C3\%ADculas.PDF

Lama, M. A. (2012). Limpieza y esterilización en quirófano de oftalmología. (Trabajo de grado). Universidad de Valladolid, Valladolid, España.
Martí, C., Alonso, R. y Constans, A. (1994). Desinfectantes: características y usos más frecuentes. Centro Nacional de Condiciones de Trabajo, NTP 429. España

Melo, J. (2009). Cuartos Limpios. Mundo HVACR. Recuperado de https://www.mundohvacr. com.mx/mundo/2009/06/cuartos-limpios/

Moia, E., \& Wheeler, F. (2000). "El criterio de diseño de una sala limpia farmacéutica”. Industria Farmaceutica, 55-63.

OMS. (2001). Buenas prácticas de manufactura establecidas or la OMS para productos farmacéuticos estériles. Series de informes técnicos de la OMS, No.961, Anexo 6.

OMS. (2005). Manual de bioseguridad en el laboratorio. (3ra ed.). Ginebra. Suiza.

Pedroza-Meléndez, A. (2012). "Las salas blancas para microelectrónica un modelo para evitar infecciones nosocomiales". Revista Mexicana de Cirugía del Aparato Digestivo, 1(2), 87-92.

Pi, R. (2006). Cualificación / Validación de zonas limpias y de riesgo. 11 Congreso Egarese "Legionella y Calidad del aire: el reto de hoy". Terrassa, España.

Red Panamericana de Armonización de la Reglamentación Farmacéutica. (2013). Buenas prácticas de la OMS para laboratorios de microbiología farmacéutica. Red PARF Documento Técnico No. 11. Washington, DC.

Reglamento Técnico Centroamericano. (2007). Productos farmacéuticos, medicamentos de uso humano, buenas prácticas de manufactura para la industria farmacéutica. RTCA 1034207.

Rueda, J., Amigot, L. y Ducha, J. (2003). "Evaluación de desinfectantes de amonio cuaternario sobre cepas bacterianas de origen animal". Scientific and Technical Review of the Office International des Epizooties, 22 (3), 1097-1104. 